\title{
Opponents stymie fight against polio in Nigeria
}

$\mathrm{T}$

here is little question that Africa's most populous nation, Nigeria, will stand out on World Polio Day.

But perhaps for the wrong reasons.

When the world marks progress toward eradicating the disease on Oct. 24, 2008, Nigeria, like the rest of Africa, can report considerable advances: the proportion of children "missed" during immunization campaigns is down from more than 50\% in 2006 throughout the north of the country to $20 \%$ in key high risk areas. That led to record-low levels of polio in 2007, particularly of transmission of poliovirus type 1 , the most dangerous type of the disease due to its propensity for geographic spread and high paralytic attack rate.

But a campaign by religious and political leaders against polio vaccinations is threatening that progress and has kept millions of children from immunization.

Now, the West African country is seeing a worrying surge in polio cases. The northern regions of the nation have even seen a new outbreak of poliovirus type 1. World Health Organizatin (WHO) officials say that as of Aug. 19, 2008, some 530 cases of type 1 polio had been reported in Nigeria, compared to 44 cases over a comparable period in 2007. The outbreak had occurred because up to $20 \%$ of children remained unimmunized in high risk northern districts.

"Additionally, this year there has already been international spread of polio from Nigeria, as virus of Nigerian origin has been detected in neighbouring countries, including Benin, Burkina Faso, Niger and Chad," says WHO polio initiative spokesperson Oliver Rosenbauer. "With intense transmission of type 1 polio in the country, the onset of the rainy season which is typically the high season for poliovirus transmission, and the expected large-scale population movements associated with the Hajj pilgrimage later this year, the risk of further international spread of this outbreak is high."

In May 2008, the World Health Assembly expressed concern at this risk of international spread and urged Nigeria to implement measures that might contain the outbreak. Nigeria has $86 \%$ of the world's cases of the wild poliovirus type

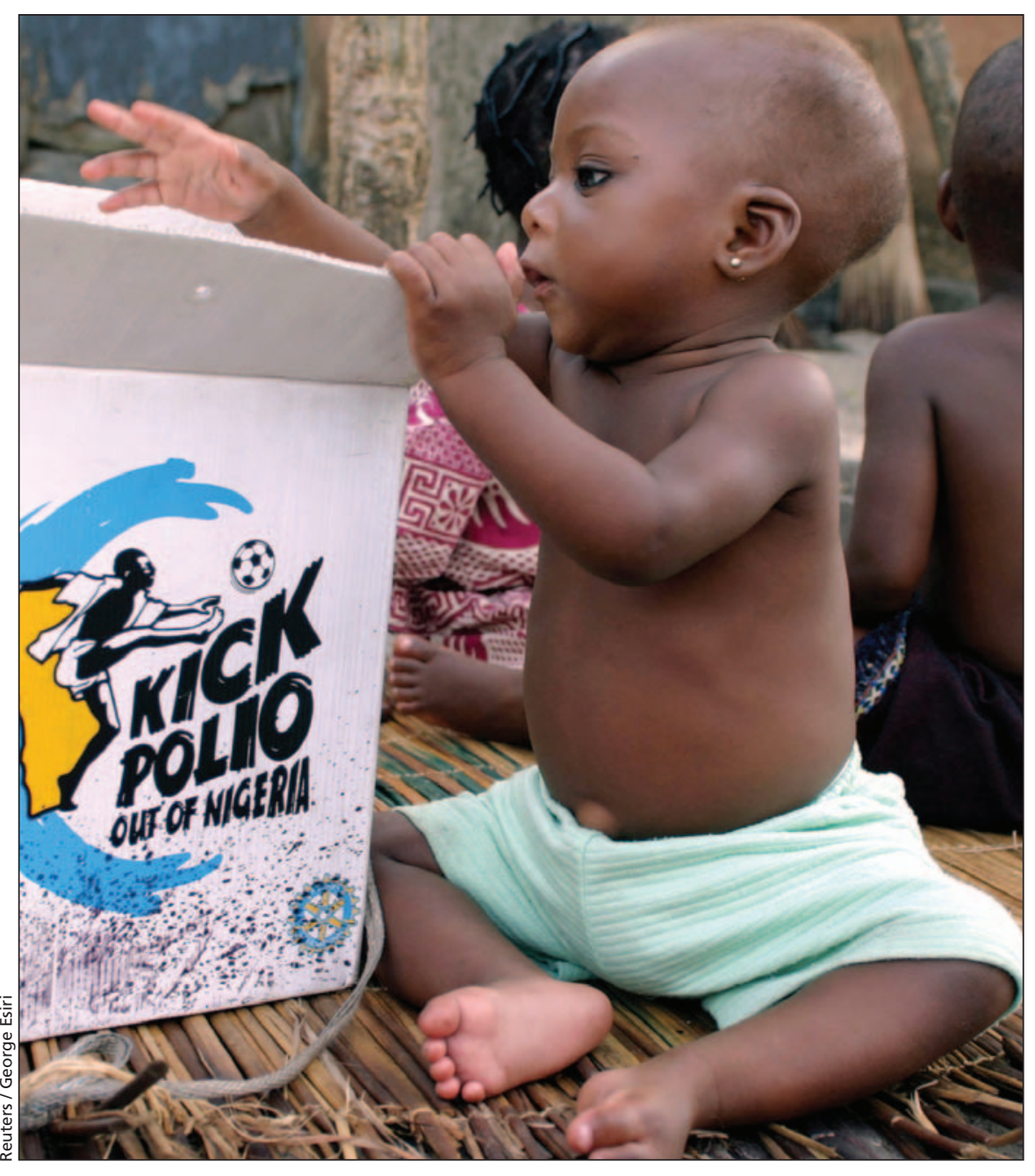

A youngster plays with a box containing polio vaccines at Ibeshe Island, $27 \mathrm{~km}$ from the Nigerian capital of Lagos. Immunization campaigns have been plagued by accusations that vaccines are a Western plot to sterilize Muslims and by bad publicity, such as a 2007 World Health Organization report that 69 Nigerian children had been paralyzed since 2005 as a result of contracting the disease from the oral polio vaccine.

1 , the cases of which have already risen 9-fold in 2008. Globally, only 4 countries are still polio-endemic: Nigeria, India, Pakistan and Afghanistan.

Kano State in northwestern Nigeria has been the epicentre of the transmission of wild poliovirus type 1 to other parts of West Africa since 2003, when the authorities suspended polio immunization for 13 months amidst claims by Muslim clerics that the vaccines were not safe. Aisha Isyaku Kiru, Kano's health commissioner, says in the first 6 months of 2008, they registered 90 polio cases, up from zero in 2007.

"While this outbreak is serious, the situation in Nigeria can be rapidly re- versed if all children are reached during every immunization campaign," says Rosenbauer. "It's key to have full political engagement and ownership at every level, to ensure the wide scale application of new tools such as monovalent OPV [oral polio vaccine] which protects children at least twice as fast against specific serotypes, and new eradication tactics tailored to the operational challenges to reaching every child."

Nigerian health officials say they are establishing mechanisms to address the operational challenges. - Wairagala Wakabi, Kampala, Uganda

DOI:10.1503/cmaj.081416 